\title{
11
}

\section{LOCAL CONTENT AND CAPABILITIES}

\section{Policy processes and stakeholders in Kenya}

\author{
Ann Kingiri and Josephat Mongare Okemwa
}

\begin{abstract}
This chapter presents a historical analysis of Kenya's policy process in renewable electrification (RE) from 1999 to 2019. The policy process reflects some efforts to promote industrialisation in the energy sector, which may be a positive step towards attainment of inclusive and sustainable development in this subsector. It is not, however, clear how these efforts translate to meaningful learning and local capabilities that are critical to building a sustainable industrialisation in emerging economies. Using novel data from a survey and secondary data, the chapter investigates changes in RE policies as far as capability development and Local Content Requirements (LCRs) are concerned and stakeholders' views about this. With the term local content, we mean the use of Kenyan local expertise, goods, and services, people and business for systematic development of national capacity, and capabilities geared towards the enhancement of the economy. The analysis of the energy policy process through the lens of capabilities identifies key policy and practice gaps that require policy support in developing requisite capabilities for support to sustainable industrialisation. From the stakeholders' survey, the majority of the stakeholders were of the opinion that deployment of technologies for RE provides opportunities for building local technical capabilities and other skills like project management.
\end{abstract}

\section{Introduction}

Interrogation of diffusion dynamics of technologies for RE has attracted attention because they are perceived to have political, social, environmental, and economic attributes, which are critical in achieving a holistic and transformational sustainable industrialisation (Schmitz and Scoones, 2015). To this end, the 
consideration of LCRs is becoming an important industrial policy tool which is largely expected to translate to local employment and private sector development. LCRs are provisions that bind foreign investors and companies to a minimum threshold that must be procured or purchased locally in order to support nascent local industries (Hansen et al., 2015; Johnson, 2015; Advisors, 2013). In Kenya there has been a change in policy dynamics to embrace industrial development in the energy sector as evidenced by inclusion of local content elements in the GoK (2019). It is however not clear how these dynamics relate to learning and capabilities that are critical to a sustainable industrialisation. This chapter interrogates the policy process resulting in the enactment of the GoK (2019). It is guided by the following overarching research questions:

i) How are industrial capacities and capabilities reflected in the Kenyan RE policy process and what are stakeholders' perspectives about this?

ii) What are the opportunities for making policies that promote capabilities related to RE in the future?

The study contributes to the on-going scholarly discussion about the prospects of a green energies revolution in contributing to sustainable industrialisation in emerging economies. The chapter is structured as follows: first the analytical framework is presented, followed by the methodology that has informed the study. Next is a critical review of capabilities and LCRs dynamics around deployment of technologies in RE based on secondary materials and perspectives of stakeholder groups (policy makers, private sector, researchers, and nongovernmental organisation - NGOs). The study concludes by drawing policy and practice-oriented lessons for an expanded discussion about inclusive renewable electrification in Kenya.

\section{Analytical framework}

The conceptual framing of this chapter benefits from the general literature on capabilities and learning as it relates to technology transfer and the structural aspects of a national innovation system (NIS). This is complemented by the industrial policy literature, primarily on the LCRs. The analytical framework looks at some basic understanding around policy making involving a dynamic technological innovation process. These theoretical concepts are used to investigate stakeholders' understanding about the key policy processes that enhance or characterise local technical and non-technical capabilities in the uptake of renewable technologies in Kenya with particular focus on wind and solar PV.

\section{Renewable technologies and capabilities}

There has been a significant growth in the number of off-grid energy firms arising from RE efforts in many countries. This has opened up research in the 
innovation and development studies scholarly fields, particularly research that focuses on low carbon technologies in emerging economies (Ockwell and Byrne, 2015). The capacity to enhance adoption of new technologies has long been known to be a key determinant of technical change in developing countries (Nelson and Pack, 1999). Further, technological capabilities are critical components of NIS (Fagerberg and Srholec, 2008), which in turn are determined by systematic policy interventions. However, the context within which sustainability technologies are being advanced and the potential for their uptake depends largely on the social and institutional ecosystem that supports the deployment process including accumulation of capabilities (Foxon and Pearson, 2008; Geels, Hekkert, and Jacobsson, 2008; Lema et al., 2018). As new technologies are introduced to a new context, the process of adaptation is determined by many institutional and structural factors including local and organisational arrangements (Sovacool, 2014; Bell, 2012). This contributes significantly to the development of a local innovation ecosystem that is critical for technological deployment more generally. Experiences of emerging countries with renewable energy technologies show that focused institutional support strengthens technology capability development ( $\mathrm{Ru}$ et al., 2012). This then implies that paying attention to local capabilities-building associated with deployment of technologies is important for strengthening respective NIS. Lema et al. (2018) argue that attention should be given to how technological capabilities are acquired. This is because there are complex and multiple user-producer interactions that demand critical thought about how technological and experiential learning occurs and how this contributes to local capabilities.

A key question for the RE efforts in Kenya has been how local capability can be strengthened in a way that promotes inclusive and sustainable industrialisation. Capability issues are important because promoting growth of specific sectors would enable a country like Kenya to create and strengthen its value addition activities including ability to design, build, and operate in these sectors. Empirical research has shown that introduction of solar PV in Kenya initially failed because of lack of local capability for appropriate installations and maintenance (Ondraczek, 2013). Other scholars have also attempted to understand the global nature of technologies for RE and what this means for local capabilities (Lema et al., 2018). These scholars note that local capabilities in wind and solar PV technologies are perceived to be important in addition to the degree to which capabilities are sought from outside Kenya and utilised by local actors. This chapter attempts to expand this scholarly field. It does so through a qualitative study carried out to understand capabilities and local content issues in the renewable electrification policy process in Kenya and stakeholders' views on this. As mentioned elsewhere, the stakeholder groups as system builders can strategically shape the technological field in which technologies in RE can develop and diffuse. This implies that they are critical in advocating for policies that could support a functional system more generally (Ockwell and Byrne, 2015). 


\section{LCRs as an industrial policy tool}

The motivation for policy makers in developing countries to promote technologies for RE is spurred by a number of factors. There is an increasing urge for RE technologies to meet not only the political, socio, and economic goals but also the transformational and sustainable goals including inclusive development (Schmitz and Scoones, 2015). The benefits emanating from renewable energy are multifaceted and include mitigating carbon emissions, which is directly connected to economic development, job creation, and other technological benefits (Lewis, 2014). Besides technical and economic benefits, another motivation relates to the ability of these technologies to enhance localised technological and innovation capabilities (Baker and Sovacool, 2017; Ockwell et al., 2018).

According to Johnson (2015), the main motivation for LCRs in developed countries is job creation. In developing countries, including sub-Saharan Africa (SSA), the motivation is mainly related to protection of nascent industries and creation of opportunities for local companies to benefit from local and foreign firms' large-scale investments (ibid). Other motivations include technology transfer, creation of new industries, and providing jobs for local people. LCRs aim to provide protection to local young firms while they accumulate capabilities to a level where they can compete with local and international firms (Hansen et al., 2015). In the RE sector, countries have used LCRs to support domestic industries. However, politics, market failures, and weak institutions are perceived to be barriers to promotion of local content (Johnson, 2015; Hansen et al., 2015). LCRs may also not create a level playing ground for global trade due to manipulation and may also lead to global trade conflicts (Ettmayr and Lloyd, 2017). When applying the LCRs' elements to specific technological innovations, Rodrik (2004) note the importance of paying attention to incentivising the very activities that allow for an expansion of the economy by generating new areas of comparative advantage. He further adds that focusing on activities across sectors has the potential to enhance interactive learning or what he refers to as crosscutting opportunities.

Policies to promote local capabilities may vary across contexts. In South Africa, the energy regulatory framework has provided an enabling environment for creation of technological capability to independent power producers. Consequently, this has enabled many local communities to have an equity share in the renewable energy projects as well as making sure that the LCRs are followed (Baker and Sovacool, 2017). In this regard, LCRs are - in many cases becoming an important industrial policy tool that have the potential to enhance domestic capabilities of local manufacturing (Johnson, 2015).

Qualitative data is used in this chapter to understand how LCRs are incorporated into RE policy instruments. Further, stakeholder views have been sought, specifically to receive more detail on the policy process and examples of policy windows to affect policy change. 


\section{Policy process and policy windows}

A policy process entails policy making and policy implementation and both have multiple elements that influence the ultimate efficiency of a policy instrument (Richardson, 1982). Policy making refers to the procedures and institutional arrangements that shape the policy process (Nilsson et al., 2012). It covers all stages of the policy cycle including problem identification, agenda setting, policy formulation, evaluation or assessment, and policy adaptation (Rogge and Reichardt, 2013). Policy implementation is where responsible authorities devise strategies to ensure efficient enforcement of specific policy instruments (Nilsson et al., 2012). It also entails actual implementation and how this is influenced by actors, for instance public service workers or street level bureaucrats who have discretion and power in policy implementation (Gilson, 2015). Efficiency may entail collaboration amongst different value chain stakeholders, provision of resources, and capacity building. Further, because of the functional dynamism of a technological system, capabilities-building at different levels including that of policy makers may be necessary (Jacobsson and Bergek, 2011). While the two aspects of the process are important, the style of policy processes is critical as a 'standard operating procedures for making and implementing policies' (Richardson, 1982, p. 2). It may provide among other things flexibility in terms of implementation of different aspects of the policy process (Rogge and Reichardt, 2013).

It is acknowledged that policy processes are complicated by the fact that many actors are involved, all with different values and interests. Indeed, policy processes in dynamic technological innovation systems like RE are associated with uncertainties linked to different expectations and interests. The solution to different vested interests may be a consideration of a policy mix whereby new policy instruments supporting particular niches may be added to already existing regimes instead of replacing them altogether (Kern and Howlett, 2009). The policy mix concept points towards mobilisation of incentives and support in a policy process while also countering potential challenges that may hinder policy support in a social technical system (Edmondson, Kern, and Rogge, 2018). This chapter takes as a point of departure the argument that the bridge between policy making and policy implementation is building requisite capabilities (institutions and human; hard and soft). These include policy innovation, managerial skills, project implementation skills, and negotiation and advocacy skills, amongst others. Debatably, policy aspects that address capabilities must be considered in the policy mix.

A better understanding of policy windows presents opportunities for learning and potential policy change. Kingdon (2003) describes how windows of opportunity for policy change can unexpectedly create a short-lived opportunity for uptake of relevant knowledge evidence which has been previously ignored. Rose et al. (2017), inspired by Kingdon's work, further note that the policy windows concept is linked to agenda setting in policy processes and may explain why 
certain policy issues gain attention in the list of policy maker's agenda. Timing is also important if research is to influence policy. In the environmental science domain, Rose et al. (2017) outline recommendations that can help both environmentalists and researchers to engage with the concept of policy windows and increase the likelihood of knowledge uptake for policy change. These include: i) capacity to foresee emergent windows like policy organisations and knowledge brokers that provide platforms for engagement, ii) capacity to respond to opening windows, iii) capacity to frame research in line with appropriate windows, and iv) capacity to persevere in closed windows which may call for arguing for incremental policy change.

This study interrogates Kenya's RE policy process to understand occurrence of policy windows in a bid to expose the extent to which capabilities as a concept has become more or less central in this process.

\section{Methodology}

The chapter builds on primary and secondary material, with empirical data having been collected as part of the IREK project. The data has provided an opportunity to generate evidence around capabilities and collaboration on renewable electrification in Kenya. Apart from the IREK stakeholder survey in 2016, the chapter draws on other sources of data, notably an analysis of policy documents thereby tracking the policy process in RE from 1999 to 2019 and documentation of IREK project interaction with key stakeholders.

In mid-2016, the IREK project undertook a survey involving stakeholders across the renewable energy sector comprising policymakers, energy professionals, academia, and NGOs. Respondents were asked to answer questions relating to their current perceptions, attitudes, and knowledge of:

- The use and practices of wind and solar technologies in Kenya.

- Current policies for solar PV and wind energy in Kenya.

- Current barriers to diffusion of technologies in these fields.

The survey placed a specific emphasis on:

- The type and extent of collaborations (local and international) within the industry that foster and enhance diffusion of solar PV and wind technologies.

- The types of capabilities/capacity building that are needed to ensure that these technologies can be effectively introduced and utilised in Kenya.

The survey was complemented by other secondary activities that were sources of data, namely:

- Analysis of stakeholders' recommendations emanating from IREK stakeholder workshops (IREK, 2015, 2018b) and insights from selected critical projects whereby interviews were conducted between 2017 and 2019. 
- Review of relevant energy policies and strategies with respect to capabilities and local content provisions.

- Interaction with Kenya's parliamentary committee on Energy, 2018 during IREK's project submission on 15 March (IREK, 2018a).

Additional primary data was generated via follow-up interviews with selected policy makers and stakeholders including those targeted for critical projects or case studies. These were conducted in 2017 in Nairobi, Kenya (see also IREK, 2017).

The survey respondents and interviewees were drawn from government institutions, research and educational institutions, think tanks, industrial associations, donors, NGOs, and the private sector in the Kenyan energy sector. Figure 11.1 presents the important actors that responded to the IREK survey as well as those interviewed at different times as part of the case studies. Together they constitute the participating stakeholders in this study.

The mapping out of all stakeholders involved in this study as outlined in Figure 11.1 serves two purposes. First, it helps us to categorise them into the different stakeholder groups they belong to. The majority of the study respondents were mainly from the research and educational institutions, private sector, and NGOs. Second, the mapping informs the discussion in the subsequent sections.

The analyses of the different sets of data followed different stages. The first stage of the data analysis focused on the perspectives of Kenya's stakeholder groups about capabilities in solar and wind subsectors based on the survey data, interviews, and case studies. The second stage entailed the analysis of data from secondary sources used to triangulate findings from the primary data. The final step entailed interrogation of the emerging perspectives using the theoretical framework adopted for this chapter.

\section{Results: prospects for building capabilities through renewable electrification}

This section documents the results of the data analysis and relevant discussion. The first part summarises the outcome of the review of key energy policies and strategies. The last parts detail the perspectives of stakeholders and how these inform policy and practice for promotion of RE local capabilities in Kenya. The latter sections discuss the results drawing on both survey data and interview data.

\section{The renewable energy policy processes in relation to local capabilities}

This section documents the energy policy processes with a view to exposing some underlying barriers and opportunities associated with capabilities and related policy change. In addition, what has changed in the RE policy landscape is also explored. The analysis pays attention to specific elements of a policy 


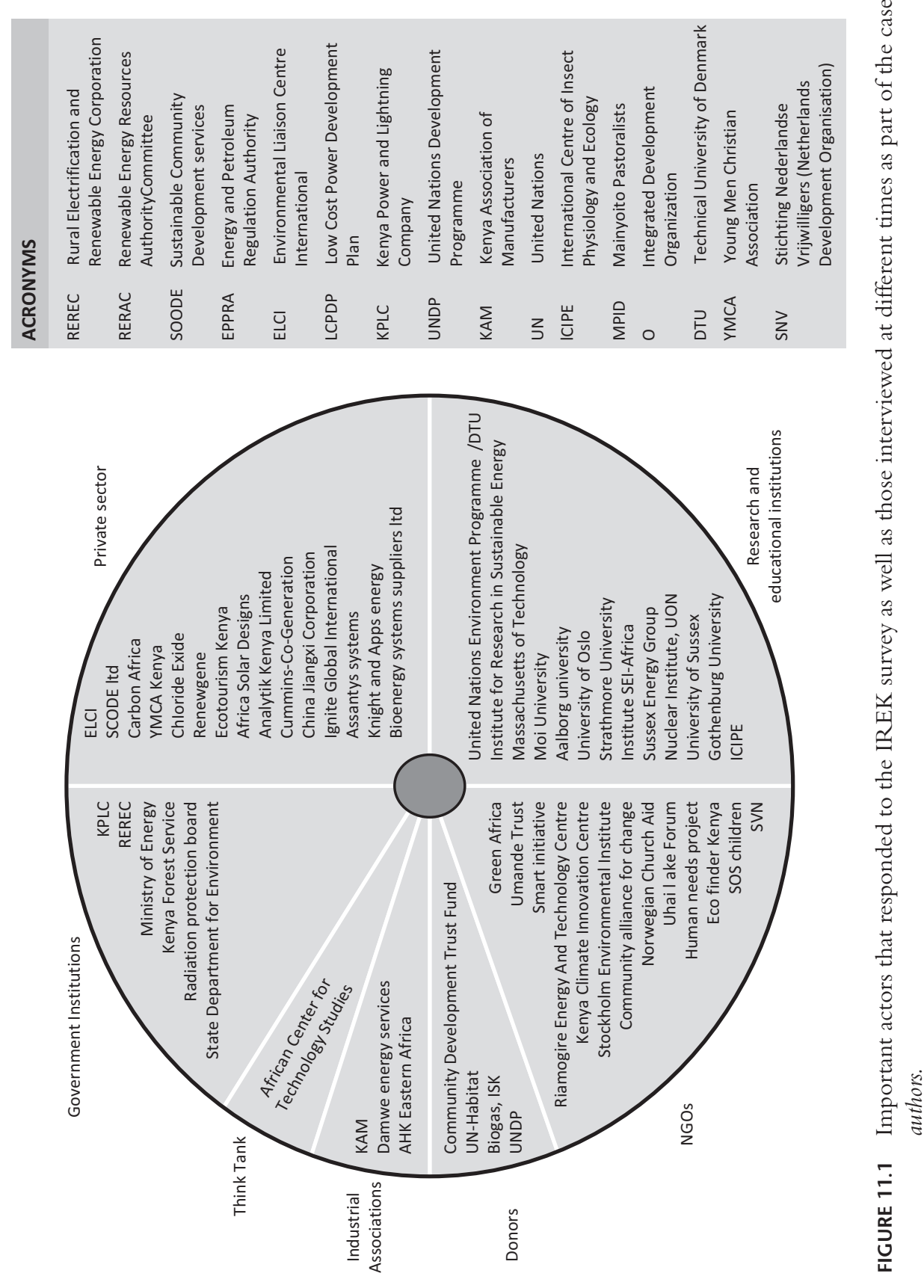


process in line with the analytical framework adopted for the chapter. The analysis also looks at the Energy Bill formulation process and the roadmap to inclusion of LCRs in the enacted policy instrument, the GoK (2019). Other relevant policy instruments that demonstrate policy related efforts to build local capabilities in Kenya's energy sector are also explored.

\section{Local content provisions in the energy policy instruments}

The energy policy formulation process has been advanced over the years mainly through the Ministry of Energy (MoE). Ogeya et al. (2022; this volume) outline the history of the different energy policy instruments that have been introduced from early 2000 to 2019. Figure 11.2 summarises these key policy instruments and the respective formulation process in relation to key actors, agenda setting, and which aspects of capabilities were given attention in each of the policies and strategies analysed.

In terms of agenda setting (circle 3 from X, Figure 11.2), the motivation for building capabilities for RE has progressively advanced, driven by different factors. In the early 2000 s, the driver of requisite policy processes was the need to diversify sources of energy and renewables targeting the off-grid population. Since then, efforts towards promotion of RE in the country have gained momentum particularly in the policy arena (Byrne, 2009). According to Makara (2019), the agenda has slowly shifted to general economic, social, and environmental goals, and more recently the promotion of local manufacturing firms as a contribution to Kenya's Big Four Agenda. This government Agenda prioritises food security, manufacturing, universal healthcare, and affordable housing, all of which depend significantly on availability of energy (ibid). Both the public and private actors have dominated the capabilities and requisite skills building efforts in different ways and times as shown in Figure 11.2, circle 2 from X. Although the RE policy roadmap may have commenced earlier, this study pays attention to the policy-making window between 1999 and 2019. For a detailed account of the policy evolution process with respect to actors (circle 2, Figure 11.2) and respective policy instruments (inner circle, Figure 11.2), see Ogeya et al. (2022; this volume).

With respect to capabilities (outer circle, Figure 11.2), there are some historical elements of capabilities-building being included in the early energy policy documents. However, the focus on capability-building and capability requirements has been limited until 2014 when the draft Energy Bill was presented to parliament and included a section on local content. The GoK (2014) and later the GoK (2018b) were consequently drafted. Both the GoK (2015a) and the GoK (2019) have local content provisions which are explored next. The GoK (2014) regulations were intended to apply to operations of all energy sources that included non-renewables and renewables. The regulations provide for a local content plan execution that includes technical and non-technical skills and capacity building targeting domestic or indigenous 


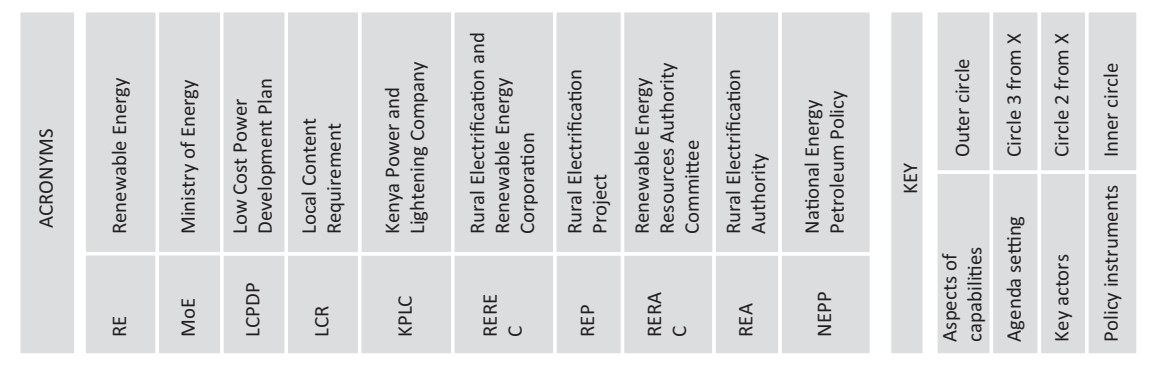

$\stackrel{3}{3}$

ํํㅎ

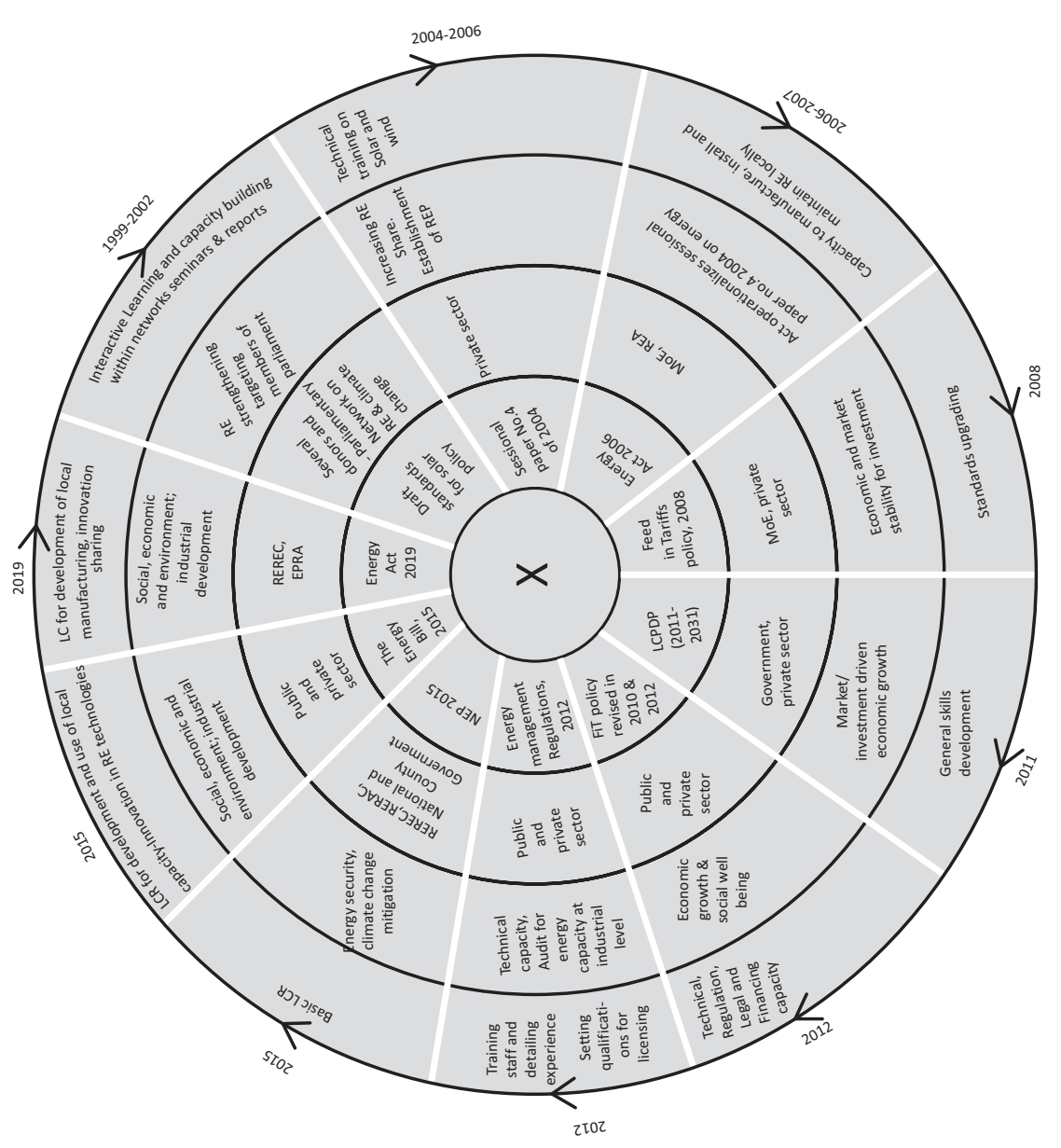


firms and prioritising local Kenyan citizens for training and employment. Local content was further popularised in 2015 when discoveries of oil were made in Kenya. The post-oil discoveries era triggered development of laws and policies that would guide oil production. The local content aspect is therefore articulated in the GoK (2015b) primarily to develop local talent and retention of value created from energy resources through appropriate policies. The policy notes that the main challenge of developing local content is lack of relevant skills and capacity. The policy further recommends capacity building in all sectors of the economy through training and international partnerships.

The drafting of the GoK (2014) may have informed the local content framing in the subsequent version of GoK (2015a) and later the GoK (2019). The GoK (2015a) strives to promote local content (LC) provisions entailing general use of local capabilities for economic growth, promotion of appropriate local capacity for the manufacture, installation, maintenance, and operation of basic renewable technologies and proposes a Renewable Energy Feed-in Tariff System to stimulate innovation in technologies for RE. The local content in the GoK (2015a) is defined as 'use of local expertise, goods and services, people, businesses and financing for development of national capabilities and for enhancement of the economy'. The LC provisions under the GoK (2019) include developing and procuring capabilities of local workforce, services, and supplies, for the sharing of accruing benefits. Further, the Act strives to promote development of appropriate local capacity for the manufacture, installation, maintenance, and operation of basic renewable technologies and as a one stop shop for information and guidance to investors on RE projects. In the GoK (2019), local content is referred to as 'added value brought to the economy from energy related activities'. There is a clear elaboration in the Act of what forms of capabilities may be anticipated in the execution of this clause and the inclusion of benefits sharing. Arguably, this may denote some flexibility in the implementation of the capability and capacity development and considers the importance of inclusivity.

The local content regulations outlined in this section point towards use of local personnel and materials. They also promote the creation of backward linkages in the value chain through requiring companies involved to utilise local firms for security, transport, clearing, and forwarding when conducting projects (see Hanlin and Okemwa, this volume).

\section{Other capabilities provisions in the energy policies and other relevant policies}

There are rules and regulations on qualifications and experiences provided for in the policy instruments that are relevant for working in the sector. There are also government minimum standards for training and skills motivated by the government intention to create an enabling environment for building individual 
skills. Kenya's Energy and Petroleum Regulatory Authority (EPRA) has been mandated to license all engineers working on solar projects. EPRA is the sole entity that regulates all electrical contractors and all electrician contractors who work on solar projects in ensuring that they are all licensed and/or that a company working on these projects has at least one licensed electrical contractor. The Kenya Bureau of Standards regulates the standards of all solar equipment that is manufactured and imported into Kenya.

In the GoK (2012), enacted under the GoK (2006), qualifications and experience for licensing range between High Diploma to Masters in Technology and Engineering related fields and a minimum of two years' work experience in energy operations or maintenance or planning. In an effort to actualise these provisions, EPRA has outlined various requirements for solar PV technicians categorised into three classes, T1, T2, and T3, before they are licensed. To be licensed for T1, one is required to be a holder of Kenya Certificate of Secondary Education (KCSE), electrical government trade test 2, and basic two years solar training experience. For T2, one is required to be a holder of KCSE, diploma, or electronic and intermediate solar training with 2 years solar installation experience; or a degree in electrical or relevant degree or higher national diploma with one-year solar installation experience. For T3, one is required to be a holder of KCSE, diploma, or electronic and advanced solar training with four years solar installation experience; or a degree in electrical or relevant degree or higher national diploma with 2 years solar installation experience.

The GoK (2019) states that a person who wishes to carry out the generation, exportation, importation, transmission, distribution, and retail supply of electricity must apply for a licence. Further, the Act requires that a person who wishes to carry out electrical installation work must be licensed as an electrical contractor by the Authority. In addition, a licence for electrical installation work shall be issued for a term of three years and may be renewed for a similar term upon expiry, subject to the licensee having undertaken any required additional training. It is important to note that, to be an electrical contractor, a person must be a certified electrical worker; or have in his employment a certified electrical worker. In addition, the Act stipulates the need for specific certification of solar system installation contractors. The two types of licensing that the Act refers to are the general electrical licensing types, namely Class A, B, and $\mathrm{C}$, and solar PV technician certificates, Class T1, T2, and T3 (see description outlined above).

Other regulations that have been gazetted to assist the local renewable electrification sector include the GoK (2018a) which provides for tax exemptions for the supply or importation of equipment and materials for development and generation of energy for solar and wind energy technologies. Similarly, the First Schedule to the GoK (2013), (revised 2018) focuses on specialised equipment for the development and generation of solar energy, including deep cycle batteries which use or store solar power. 


\section{Insights from stakeholders: prospects for building capabilities through renewable electrification in Kenya}

This section documents capabilities in the RE policy process in Kenya and stakeholders' views on the same.

\section{Perspectives of stakeholder groups about capabilities in solar and wind subsectors in Kenya: insights from survey and interviews}

This study and the broader IREK project was motivated by an underlying hypothesis that promoting (technological) capabilities in certain industries enables a country to create and strengthen its value addition activities in the relevant subject area; in this case in the ability to design, build, and operate solar PV and wind projects. The 2016 survey and follow-up interview questions were designed to elicit perspectives about whether and how RE efforts in Kenya contribute to raising different forms of technical and managerial capabilities. The majority of the stakeholders noted that promotion of renewable technologies (usually from abroad) significantly increases the ability for local technical and managerial capabilities to be built. This implies that capabilities are built from the interactions or collaborations within and outside the projects. The majority of stakeholders argued that mechanisms for knowledge generation and diffusion associated with different forms of capabilities in both wind and solar subsectors were weak when the survey was conducted in 2016. This calls for strategies to strengthen the linkages between knowledge supplies and users in a way that promotes learning and consequently local capabilities in these sectors.

Respondents to the 2016 survey were further asked to identify areas where capabilities are strong or lacking in the wind and solar PV technology sectors in Kenya. They were required to select from i) equipment manufacturing, ii) project development, iii) construction and installation, iv) operations and maintenance, and v) training. The study shows that equipment manufacturing capability is significantly low in both subsectors (Figure 11.3). Respondents argued that this may be the main reason why local projects rely heavily on foreign firms for acquisition and supply of energy generating equipment. The international transfer of technology is arguably an indication of top down transfer flow of knowledge. This is attributed to the undeveloped stage of Kenya's local manufacturing sector (Lema et al., 2018). Capability in operations and maintenance was a bit more developed, particularly in the solar subsector, which may denote opportunity for local capability deployment at the lower level of technology manufacturing and the deployment chain. This was corroborated by followup interviews. One entrepreneur dealing in solar PV noted that 'solar does not require frequent maintenance and it is easy to identify trained solar PV technicians all around Kenya ... and in the case of wind, technicians with knowhow and experience are lacking' (interview on 13 February 2017). 

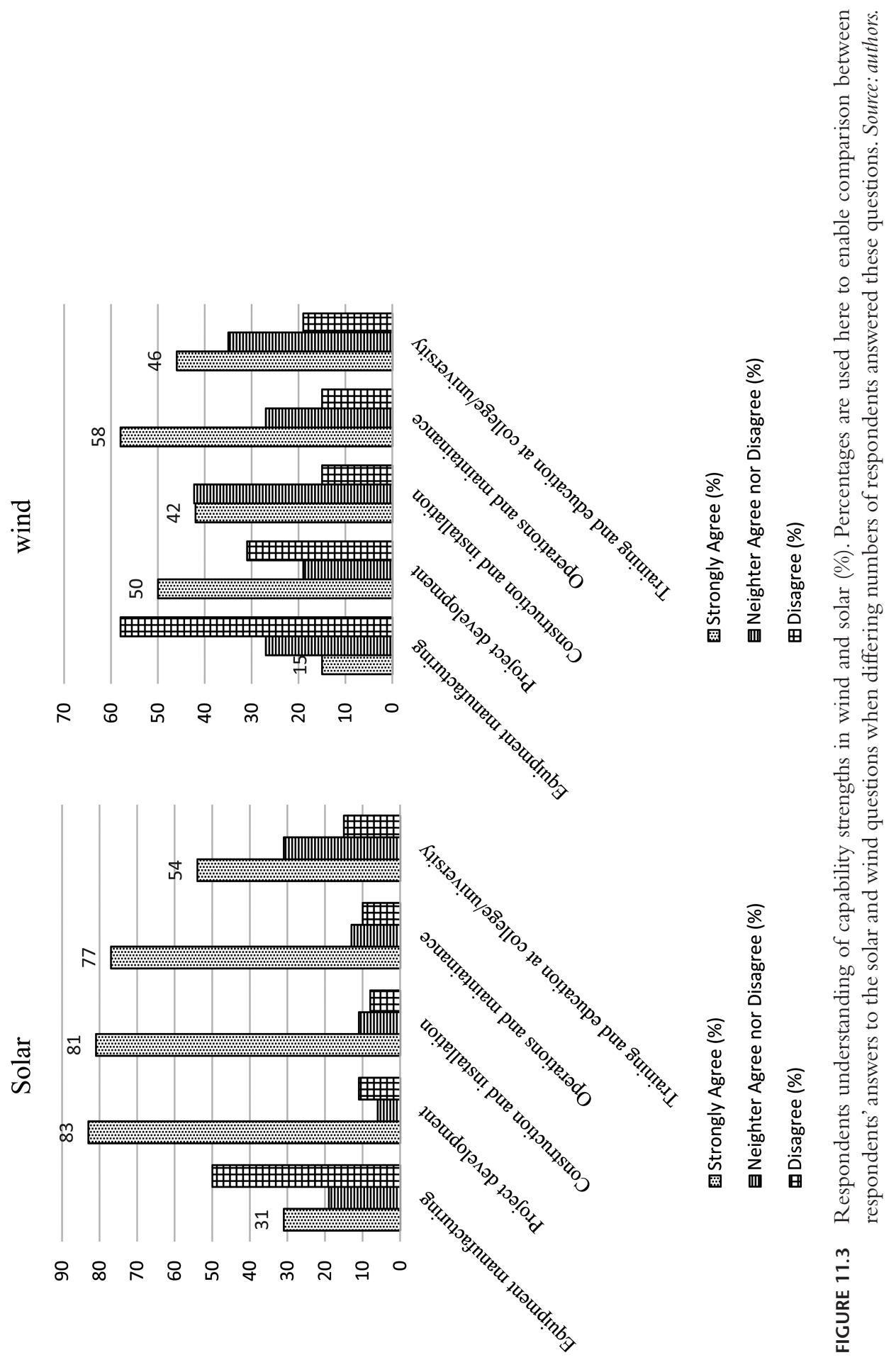
The respondents noted that lack of local training and education in these subsectors has confounded the weak local capabilities situation. Arguably, training and education at college level may contribute to basic knowledge as is the case with solar technicians but this may not guarantee attainment of practical knowledge that is relevant for sustained local capability. The majority of the respondents identified the importance of capacity for managing networking including international relationships to enhance successful technology transfer. This is a non-technical skill that needs to be built at the local level. Lema et al. (2018) contend that both manufacturing and deployment chains of solar PV and wind turbines may promote interactive learning, but that such options are frequently ignored in informing requisite policy and practice.

\section{Perspectives of stakeholders about capabilities: insights from selected case studies}

The IREK project has been studying some critical projects whereby qualitative data involving interviews with key persons on these projects further exposes mixed reactions about policy support for building local capabilities (see also Hanlin, Okemwa, and Gregersen, 2019). A number of these reactions are reported next.

\section{A supportive policy environment is critical to capabilities-building}

Government actions and policy initiatives have the power to create an enabling environment through which capabilities can be built. For instance, some respondents from selected case studies perceived that the Kenyan government and other institutions have supported renewable energy sector development through formulation of conducive policies. One programme director from a solar project noted that 'the environment is now favourable as policies governing the sector are in place as compared to when the project had no policy guidelines during the earlier stages of project installation' (interview on 7 February 2019). The respondent argued that this provides an opportunity for building of capabilities, collaborations, and job creation more generally. An engineer in one of the case study solar projects under the IREK research project argued that the policy environment and regulations provided guidance to the recruitment of engineers and technicians with the right qualifications including recruitment of project staff and contractors in the supply chain (interview on 4 March 2019). This was corroborated by a key staff member of a firm that was contracted to design, supply, and undertake installations works including electrical for power distributions (interview on 18 January 2019). He noted that existing regulations required the engineers and technicians from the contracting firm to be licensed by the government through REREC (formerly known as Electricity Regulatory Commission - ERC). The regulations further required the firm to develop an organisational policy that would 
ensure staff undertake training to acquire additional new skills. These sentiments were echoed by a senior manager working with the government, who asserted that the government is partnering with stakeholders to establish specialised academies or centres of excellence for specialised training in specific areas of renewable energy (interview on 28 February 2017). An interview with a co-founder of one of the wind firms affirmed government policy support by noting that 'the government has been very supportive and proactive in spite of the bureaucracy and lack of coordination'. He added that 'the wind firm has survived under different governments and as such, local knowledge on how to manage and develop the project has been acquired to date' (interview on 6 February 2017). These findings seem to suggest that government support is critical in ensuring a favourable policy environment to build local capabilities.

\section{Lack of commitment to support policies that are important for capabilities-building by stakeholders}

Others had mixed feelings about the policy support emanating from the government, especially for relatively small projects. One pessimistic respondent from a solar project cited lack of commitment to support policies for collaborative small projects, which he considered to be major contributors to economic and sustainable development. He remarked 'a big ten megawatt project will help few people get jobs, however small scale projects will create tens of thousands of jobs but the government is not having a vision to do that' (interview on 22 January 2019). He further noted that the net metering policy has not been implemented and small projects have not benefitted. He called for the national and county governments to collaborate in the implementation of relevant policies that support RE technologies for the poor. This purported lack of policy support to the grassroots projects was confirmed by a policy regulator who lamented 'there is lack of proper incentives from the government to support renewable energy industry ... raw materials and equipment are not locally available and the cost of power is high'. The regulator further added 'generally, there is little support from the government to support the local fabrication' (interview on 23 January 2019).

Sentiments relating to another fourth solar project identified collaboration issues. A county official informed that the local beneficiaries had not been involved in major decisions pertaining to this project's launch as well as benefits sharing. The other issue was lack of clear policy guidelines on skills development targeting local staff. A technician who was interviewed on this project mentioned that a training contract between the government and the contracted company was drawn. This provided for Kenyan local engineers to receive handson training to acquire skills for day-to-day monitoring of the unit which at the time of the interview had not been carried out. The respondent perceived that this had not been forthcoming because foreign staff preferred working at night and as such, local engineers were unable to learn these skills (interviews with 
three people between 13 and 15 February 2019). This may be interpreted as lack of commitment to support policies that are important for capabilities-building.

\section{Prospects for building local capabilities through RE: summing up the stakeholders' views}

Overall, the majority of the stakeholders argued that mechanisms for knowledge generation and diffusion associated with different forms of capabilities in both subsectors are currently weak. This calls for strategies to strengthen the linkages between knowledge supplies and users in a way that promotes learning and consequently local capabilities. We note and argue that local universities and colleges have a role to promote capabilities at both the manufacturing and deployment chains through appropriate education and training. However, combining or integrating practical knowledge in the formal technical training is an issue for policy and requires critical thought. The study further identified the complexity around technology transfer and local capability-building. Debatably, the expected knowledge transfer from international or foreign firms should be complemented with requisite local training to enhance skills that can contribute to sustainable uptake of renewable technologies.

Stakeholders acknowledge that Kenya's policy process in renewable energy has been shaped by multiple actors who are critical in providing direction for the manufacturing and deployment of solar and wind technologies in Kenya. Academic literature has also credited stakeholders for their role in creating a conducive regulatory and policy environment and for undertaking dynamic system-building processes (Jacobsson and Bergek, 2011; Bergek et al., 2008). Further, depending on the nature of interactions, different actors in the value chain stimulate learning through the functions they undertake. This provides an opportunity for local capability-building (Lema et al., 2018).

\section{Discussion}

\section{Advocating for capabilities-building in RE policy and practice}

The literature on policy windows discussed earlier in this chapter demonstrates how to promote evidence-informed policy. As part of policy research under IREK, the research team got an opportunity to make an oral and written submission on the Energy Bill to the Energy parliamentary committee in early March 2018 (IREK, 2018a). The submission to the policy makers was supported by case studies and examples of success in respective counties. One of the parliamentarians reacting to the presentation expressed lack of awareness about one case study project under IREK that purportedly has great potential for building domestic skills. The IREK recommendations to the committee emphasised the need to incorporate commitments for capabilities-building for enhanced renewable energy uptake in the Energy Bill and the need to launch renewable technology 
studies. This may be perceived to be an unexpected 'window of opportunity' for IREK research to influence policy change. Arguably, this intervention may be linked to inclusion of flexible, capabilities-oriented, local-content elements in the GoK (2019). Seizing upon a policy window by publishing a compilation of relevant knowledge on capabilities is in agreement with recommendations to develop specific tips for approaching policy windows (Rose et al., 2017).

The IREK policy research has also demonstrated the importance of policy mixes and how this might influence renewable technological uptake and the embedded local capabilities-building in the Kenyan context. Depending on context, policy mixes may be a prerequisite for a positive policy outcome in the field of sustainability transitions (Edmondson, Kern, and Rogge, 2018). Interviews conducted by IREK team members confirm this. For instance, a respondent from a critical solar project under IREK, who previously served as a technician and a manager, remarked 'the government from one of the counties in Kenya issued us with an allotment letter for the land where the project is installed' (interview on 26 February 2019). The national policy was not enough for the implementation of the project and the county policy was complementary. The policy mix in relation to capabilities is inconclusive from this study and hence warrants further research.

\section{Prospects for building local capability through LCRs}

It is important to note that the local content idea is not new in Kenya's energy policy process. Byrne (2009, p. 148) noted that in the early 2000s when discussions about renewable energy were gaining currency, the formulation of standards for solar PV then considered local content, citing the importance of protecting local manufacturers. The formulation team was made up of mainly policy makers and technical experts under the Ministry of Energy then. Strangely, this motivation was not long lived because the GoK (2006) does not have local content provisions. These, however, are included in the GoK (2015a) and finally in the enacted GoK (2019). Despite politics, the latter years of the energy policy process may be perceived to have been more participatory and inclusive in terms of agenda setting. Following a public invitation to make submissions related to the Energy Bill, subsequent activities of strategic actors like the IREK team and other stakeholders may have influenced the policy-making process. Capacity to seize a window of opportunity (Rose et al., 2017) to underline the importance of local capabilities may arguably have been critical.

There have been subtle motivations to invest in local capabilities as revealed by this study. According to a respondent from a private sector it should be a normal practice to give priority to local companies or to engage labour from locals in projects (interview on 8 February 2017). However, this has not been always the case. Previously, before the enactment of the GoK (2019), we may conclude that local capacity building efforts by different stakeholders were unstructured and ad hoc. A senior respondent from a government institution asserted that 
'the Chinese do not use local subcontractors but because of local (government) push, this is changing'. He further added that in an effort to encourage knowledge transfer through LCRs, 'we try to enforce training and local employment' (interview on 8 February 2017). Another interviewee from a private company with a 15-year maintenance contract in a wind company corroborates this purportedly changing trend. He informed us that

during the initial stages of installation, we had 5\% local and 95\% foreign engineers. However, this has changed over time with more locals now taking the role. In addition, frequent maintenance due to wear and tear of turbines allows for local training.

(Interview on 8 February 2017)

One foreign entrepreneur interested in developing local capacity in the wind sector lamented that in a previous tender with the government, the signed contract did not provide for equipment maintenance, which resulted in system failure due to negligence (interview on 8 February 2017).

The local content policies in Kenya have been criticised for having a limited impact in the energy sector including mining or mineral extraction (Mwendwa, 2019). This notwithstanding, the Energy Act (2019) creates 'a window of opportunity' for stakeholders in renewable energy to ensure that the implementation of LCRs takes into cognisance the need to develop capabilities of local manufacturers. Realising the opportunities will however require collaboration between the local and international actors as well as the policy actors at the local level.

\section{Conclusion and recommendations}

This chapter focuses on capability-building and local contents issues in the RE policy process in Kenya between 1999 and 2019 and set out to answer the following questions: i) how are industrial capacities and capabilities reflected in the Kenyan RE policy process and what are stakeholders' perspectives about this?; and ii) what are the opportunities for making policies that promote capabilities related to RE in the future? Through the lens of stakeholders in the energy sector and analysis of key secondary documents, the study identifies interesting dynamics that help us answer these questions.

To start with, the findings from the stakeholders' survey indicate that deployment of technologies for RE has provided opportunities for building local technical capacities and managerial capacities. In addition, the analysis of the policy process has shown that there has been a steady process relating to inclusion of capabilities provisions in the energy policy instruments. At the early phases (in reference to GoK, 2006), capabilities-building was synonymous with human resource development, i.e., developing skills and competences of technicians and engineers to deal with the RE technologies. In later phases, there was more emphasis on local content issues and capability development in policies and strategies. 
The analysis has identified key policy and practice gaps that require policy support in developing requisite capabilities for support to sustainable industrialisation of the sector.

The results show that there is partial application of the capability concept in the process and in particular the application of LCRs for solar PV and wind technologies for Kenya's RE, especially in the early phases of the process that culminated into the enactment of the GoK (2019). The results further demonstrate that there were different factors and actors that influenced the agenda setting and ultimate policy outcome. The policy process at the early phases was motivated by the urge to increase the share of RE in the country's energy mix. The agenda progressively shifted to embrace local economic oriented interests like industrial development and global environmental goals. The inclusion of local content provisions in the GoK (2015a) and ultimately in the GoK (2019) may be perceived to be a protracted path towards industrialisation through promotion of local capabilities for economic growth.

The study has established that although capabilities in the solar sector are more advanced than wind, overall capabilities are inadequate in both sectors to steer a sustainable industrialisation. The stakeholders put emphasis on building capabilities in the operations and maintenance field, especially in the wind subsector, and a corresponding perception that Kenya does not have to rely on foreign firms for operations and maintenance expertise. From the broader IREK work and as recorded in Hanlin, Okemwa, and Gregersen (2019) and in other chapters in this book (for instance Hanlin and Okemwa, 2022; this volume; Karjalainen and Byrne, 2022; this volume), there is evidence that Kenya is progressively building capacities in operation, maintenance, and service skills for both wind and solar PV. However, more support is needed in this area and as a first step there is a need for more research in this regard.

The survey in particular shows that Kenya does not have huge manufacturing capacity and given the likelihood of an upward trend in increased influx of technologies for RE in the future, there is a need for policy makers to rethink where to direct requisite policy support. For instance, should they focus on building an industrial manufacturing base and try to become the source of solar PV or wind equipment manufacturers whose products are then exported? Or should the attention be on increasing access to energy, thereby reducing energy poverty and working towards national climate change targets? The former fits with the focus on longer-term job creation and economic growth that was emphasised by so many of the survey respondents. However, so too does a focus on ensuring $100 \%$ access to electricity (whether grid connected or otherwise), at least in the short and medium term until the country has been fully electrified through jobs building renewable power plants and maintaining them. A key question that requires more research by academics and more consideration by policy makers is whether focusing on increasing access to energy utilising foreign technology creates transferable skills and opportunities for employment and viable operations and maintenance businesses beyond the wind and solar PV subsectors. 
Training is one way to enhance future opportunities for requisite capacity building and policy change in RE. With regards to training needs in the solar and wind subsectors, the study raises a key need for more assessment of the current situation to be conducted. This requires action not just by the Government of Kenya but also firms and other actors involved in solar PV and wind projects in Kenya to ensure that they have adequately trained staff. More research on the level of in-house training that takes place within firms and organisations involved in this field would provide interesting additional context. The education system should also investigate more on what specific training may be useful to develop at Kenyan universities and Technical Vocational Education and Training Institutions (TVET). A review of county level vocational training efforts, particularly in counties that have large or large numbers of renewable energy projects, would be helpful in this regard. All these issues relate to lack of clarity on factors that motivate the policy makers to prioritise capability-building.

Both private and policy actors have influenced the energy policy process but largely without taking cognisance of holistic capabilities, including technical and managerial capabilities, as well as capabilities along the local manufacturing value chain. This study has shown that stakeholder groups (policy makers, private sector, researchers, and NGOs) as system builders can strategically shape the technological field in which technologies in RE can develop and diffuse. Consequently, it is noted that windows of opportunities for learning and building capabilities at different scales in RE are maximised when stakeholders collaborate and where there is policy support. Further, stakeholders have a role to play in influencing the direction of policy change but only if they develop the capacity to seize windows of opportunity and use practical evidence for training and advocacy.

Based on the results of this study, policy and practice recommendations should build on the following lessons learned:

- Stakeholders have different understanding of capabilities. This can impact negatively on capabilities-building efforts. There is therefore a need for continued awareness creation amongst different stakeholders, especially policy makers and academics.

- Evidence is critical in influencing the perspectives of policy makers about the need for a policy change, in this case the importance of capabilities in RE.

- In addition to evidence, timing of engagement during the policy formulation process is paramount. Researchers engaging in policy processes have a high probability of influencing policy outcome where a window of opportunity arises.

- A comprehensive framework for review of energy policies should guide in the subsequent implementation. There should also be consideration for policy mix because the energy sector is dynamic and attracts interest in other non-energy policy domains. 
Overall, the findings suggest the importance of building a strong capacity in the area of solar PV and wind energy in Kenya. The stakeholder survey identifies areas where the capacity is low or may be needed. Arguably, RE for sustainable industrialisation can only be realised if there is a conducive policy environment that supports training opportunities, uptake of RE technologies and investment, as well as collaboration. This notwithstanding, Kenya needs to find its own way forward based on in-depth analysis of its natural resources and capacity for change (see for instance Schmitz, 2007; Schmitz and Scoones, 2015). This should then inform strategic direction in the implementation of the enacted Energy Act (2019) and in particular the local content aspects in order to enhance sustainable industrialisation. To this end, the government could proactively work to boost production capability of local actors for both wind and solar technologies.

\section{Acknowledgement}

This research is supported by the Danish Ministry of Foreign Affairs, Grant: DFC 14-09AAU. The authors acknowledge this support.

\section{References}

Advisors, W.T.I. (2013) 'Local content requirements and the green economy' in Ad Hoc Expert Group Meeting on Domestic Requirements and Support Measures in Green Sectors: Economic and Environmental Effectiveness and Implications for Trade, June, pp. 13-14. Available: at: https://acf2017.africacarbonforum.com/sites/default/files/documents/ DITC_TED_13062013_Study_WTI.pdf (Accessed: 2/10/2021)

Baker, L. and Sovacool, B.K. (2017) 'The political economy of technological capabilities and global production networks in South Africa's wind and solar photovoltaic (PV) industries', Political Geography, 60, pp. 1-12. https://doi.org/10.1016/j.polgeo.2017.03 .003

Bell, M. (2012) Low-Carbon Technology Transfer. Low-Carbon Technology Transfer: From Rhetoric to Reality. London: Routledge. https://doi.org/10.4324/9780203121481

Bergek, A., Jacobsson, S., Carlsson, B., Lindmark, S., and Rickne, A. (2008) "Analyzing the functional dynamics of technological innovation systems: A scheme of analysis", Research Policy, 37(3), pp. 407-429. https://doi.org/10.1016/j.respol.2007.12.003

Byrne R.P. (2009) Learning Drivers: Rural Electrification Regime Building in Kenya and Tanzania. DPhil Thesis. Brighton, UK: University of Sussex.

Edmondson, D.L., Kern, F. and Rogge, K.S. (2018) The co-evolution of policy mixes and socio-technical systems: Towards a conceptual framework of policy mix feedback in sustainability transitions', Research Policy, 48 (10). https://doi.org/10.1016/j.respol .2018 .03 .010

Ettmayr, C. and Lloyd, H. (2017) 'Local content requirements and the impact on the South African renewable energy sector: A survey-based analysis', South African Journal of Economic and Management Sciences, 20(1). https://doi.org/10.4102/sajems.v20i1.1538

Fagerberg, J., and Srholec, M. (2008) 'National innovation systems, capabilities and economic development', Research Policy, 37 (9), pp. 1417-1435. https://doi.org/10.1 016/j.respol.2008.06.003 
Foxon T. and Pearson, P. (2008) 'Overcoming barriers to innovation and diffusion of cleaner technologies: Some features of a sustainable innovation policy regime', Journal of Cleaner Production, 16 (1), pp. 148-161. https://doi.org/10.1016/j.jclepro.2007.10 .011

Geels, F.W., Hekkert, M.P. and Jacobsson, S. (2008) 'The dynamics of sustainable innovation journeys', Technology Analysis \& Strategic Management, 20 (5), pp. 521-536. https://doi.org/10.1080/09537320802292982

Gilson, L. (2015) 'Michael Lipsky's street-level bureaucracy: Dilemmas of the individual in public service' in: Balla, Steven J., Lodge, Martin, and Page, Edward (eds.), The Oxford Handbook of Classics in Public Policy and Administration. Oxford: Oxford University Press.

Government of Kenya (GoK) (2006) 'The Energy Act 2006, Legal Notice No. 102 of 2006'. http://www.eisourcebook.org/cms/Kenya\%20Energy\%20Act,2006.pdf (Accessed: 10/01/2020)

GoK (2012) 'The Energy (Energy Management) Regulations 2012'. https://www.epr a.go.ke/download/the-energy-energy-management-regulations-2012/ (Accessed: $10 / 10 / 2019)$.

GoK (2013) 'Value Added Tax Act, (2013)'. Chapter 476. Revised Edition 2012 [1993]. www.kenyalaw.org (Accessed: 10/01/2020).

GoK (2014) 'Energy (Local Content) Regulations, 2014'. Available at: https://energy.go $. \mathrm{ke} / ? \mathrm{p}=237$ (Accessed: 10/10/2019).

GoK (2015b) Draft Energy Bill. 154p. Republic of Kenya: GoK.

GoK (2015a) 'Draft national energy and petroleum policy (NEPP)'. http://www.erc.go .ke/images/docs/National_Energy_Petroleum_Policy_August_2015.pdf

GoK. (2018a) 'Finance Act (2018)'. Special Issue, Kenya Gazette Supplement No. 121 (Acts No. 10).

GoK (2018b) 'Local Content Bill (2018)'. http://www.parliament.go.ke/node/10677 (Accessed: 10/01/2020).

GoK (2019) 'The Energy Act, 2019', no. Acts No. 1 (2019).

Hanlin, R., Okemwa, J. and Gregersen, C. (2019) 'Building competences and capabilities through projects: Examples from Kenya's renewable energy sector', IREK Working Paper No. 8. http://irekproject.net (Accessed: 10/10/2019).

Hanlin, R. and Okemwa, J. (2022) 'Interactive learning and capability-building in critical projects', in Building Innovation Capabilities for Sustainable Industrialisation: Renewable Electrification in Developing Economies. New York: Routledge. https://doi .org/10.4324/9781003054665-7

Hansen, M.W., Buur, L., Kjær, A.M. and Therkildsen, O. (2015) 'The economics and politics of local content in African extractives: Lessons from Tanzania, Uganda and Mozambique', Forum for Development Studies, 43 (2), pp. 201-228. https://doi.org/10 $.1080 / 08039410.2015 .1089319$

Innovations and Renewable Electrification in Kenya (2015) 'Drivers for uptake of renewable electrification in Kenya', IREK Briefing Note No. 1, Feb. Available at: http://irekproject.net (Accessed: 10/10/2019).

IREK (2017) 'Insights from joint research interviews', Briefing Note No. 3, Feb. Available at: http://irekproject.net (Accessed: 10/10/2019).

IREK (2018a) 'Embedding capabilities in energy policies for effective deployment of renewable technologies: IREK project policy intervention', Briefing Note No. 5, March. Available at: http://irekproject.net (Accessed: 10/10/2019). 
IREK (2018b) 'Towards a functional renewable energy sector in Kenya: Recommendations from stakeholders', Briefing Note No. 6, March. http://irekproject.net (Accessed: 10/10/2019).

Jacobsson, S. and Bergek, A. (2011) 'Innovation system analyses and sustainability transitions: Contributions and suggestions for research', Environmental Innovation and Societal Transitions, 1(1), pp. 41-57. https://doi.org/10.1016/j.eist.2011.04.006

Johnson, O. (2015) 'Promoting green industrial development through local content requirements: India's National Solar Mission', Climate Policy, 16 (2), pp. 178-195. https://doi.org/10.1080/14693062.2014.992296

Karjalainen, J. and Byrne, R. (2022) 'Moving forward? Building foundational capabilities in Kenyan and Tanzanian off-grid solar PV firms', in Building Innovation Capabilities for Sustainable Industrialisation: Renewable Electrification in Developing Economies. New York: Routledge. https://doi.org/10.4324/9781003054665-9

Kern, F. and Howlett, M. (2009) 'Implementing transition management as policy reforms: A case study of the Dutch energy sector', Policy Sciences, 42(4), pp. 391-408. https://doi.org/10.1007/s11077-009-9099-x.

Kingdon, J. (2003) Agenda, Alternatives, and Public Policies. 2nd ed. New York: Longman Press.

Lema, R., Hanlin, R., Hansen, U.E. and Nzila, C. (2018) 'Renewable electrification and local capability formation: Linkages and interactive learning', Energy Policy, 117, pp. 326-339. https://doi.org/10.1016/j.enpol.2018.02.011

Lewis, J.I. (2014) 'The rise of renewable energy protectionism: Emerging trade conflicts and implications for low carbon development', Global Environmental Politics, 14 (4), pp. 10-35. https://doi.org/10.1162/glep_a_00255

Makara, M. (2019) 'Affordable and reliable energy pivotal to Kenya's delivery of its 'Big Four Agenda': Kenya's energy sector can enhance the country's economic growth', Africa Business Insight, Maritz Africa. 12 June. Available at: https://www.howwemad eitinafrica.com/affordable-and-reliable-energy-pivotal-to-kenyas-delivery-of-its -big-four-agenda/63351/ (Accessed: 20/02/2020).

Mwendwa, D. (2019) 'The development of local content in the oil and gas industry in Kenya: The need for negotiations'. https://www.researchgate.net/publication/3352 43350 _THE_DEVELOPMENT_OF_LOCAL_CONTENT_IN_THE_OIL_ AND_GAS_INDUSTRY_IN_KENYA_THE_NEED_FOR_NEGOTIATIONS (Accessed: 23/06/2020).

Nelson, R. and Pack, H. (1999) 'The Asian miracle and modern growth theory', The Economic Journal, 109 (457), pp. 416-436. http://www.jstor.org/stable/2565712 (Accessed on 2/10/2020).

Nilsson, M., Zamparutti, T., Petersen, J.E., Nykvist, B., Rudberg, P. and McGuinn, J. (2012) 'Understanding policy coherence: Analytical framework and examples of sector-environment policy interactions in the EU', Environmental Policy and Governance, 22 (6), pp. 395-423. https://doi.org/10.1002/eet.1589

Ockwell, D. and Byrne, R. (2015) 'Improving technology transfer through national systems of innovation: Climate relevant innovation-system builders (CRIBs)', Climate Policy pp. 1-19. https://doi.org/10.1080/14693062.2015.1052958

Ockwell, D., Byrne, R., Hansen, U.E., Haselip, J. and Nygaard, I. (2018) 'The uptake and diffusion of solar power in Africa: Socio-cultural and political insights on a rapidly emerging socio-technical transition', Energy Research and Social Science, 44, pp. 122-129. https://doi.org/10.1016/j.erss.2018.04.033 


\section{Ann Kingiri and Josephat Mongare Okemwa}

Ondraczek, J. (2013) 'The sun rises in the east (of Africa): A comparison of the development and status of solar energy markets in Kenya and Tanzania', Energy Policy, 56, pp. 407-417. https://doi.org/10.1016/j.enpol.2013.01.007

Richardson, J. (1982). Policy Styles in Western Europe (Routledge Revivals) (1st ed.). London, UK: Routledge. https://doi.org/10.4324/9780203082010

Rodrik, D. (2004) 'Industrial policy for the twenty-first century', SSRN Electronic Journal. Available at SSRN: https://ssrn.com/abstract=617544 or http://dx.doi.org /10.2139/ssrn.617544

Rogge, K.S. and Reichardt, K. (2013) 'Towards a more comprehensive policy mix conceptualization for environmental technological change: A literature synthesis', Working Paper Sustainability and Innovation, No. S3/2013, Fraunhofer ISI, Karlsruhe. http://hdl.handle.net/10419/77924 (Accessed on 2/ 10/2020).

Rose, D.C., Mukherjee, N., Simmons, B.I., Tew, E.R., Robertson, R.J. Vadrot, A.B.M., Doubleday, R. and Sutherland, W.J. (2017) 'Policy windows for the environment: Tips for improving the uptake of scientific knowledge', Environmental Science and Policy, 113(November 2020), pp. 47-54. https://doi.org/10.1016/j.envsci.2017.07.013

Ru, P., Zhi, Q., Zhang, F., Zhong, X., Li, J. and Su, J. (2012) 'Behind the development of technology: The transition of innovation modes in China's wind turbine manufacturing industry', Energy Policy 43, pp. 58-69. https://doi.org/10.1016/j.enpo 1.2011.12.025

Schmitz, H. (2007) 'The rise of the East: What does it mean for development studies?', IDS Bulletin, 38(2), pp. 51-58. https://doi.org/10.1111/j.1759-5436.2007.tb00351.x

Schmitz, H. and Scoones, I. (2015) 'Accelerating sustainability: Why political economy matters', IDS Evidence Report 152. Brighton, UK: Institute of Development Studies. https://opendocs.ids.ac.uk/opendocs/handle/20.500.12413/7077 (Accessed on 1/10/ 2020).

Sovacool, B.K. (2014) 'Energy studies need social science', Nature 511, pp. 529-530. https ://doi.org/10.1016/j.jeem.2008.02.004 